Int. J. Dev. Biol. 50: 135-141 (2006)

doi: $10.1387 / \mathrm{ijdb} .052102 \mathrm{nb}$

\title{
A hypothesis linking low folate intake to neural tube defects due to failure of post-translation methylations of the cytoskeleton
}

\author{
NATALIE K. BJÖRKLUND ${ }^{1}$ and RICHARD GORDON ${ }^{2,3,4, *}$ \\ Manitoba Institute of Cell Biology ${ }^{1}$, Radiology ${ }^{2}$, Computer Science ${ }^{3}$ and Electrical \& Computer Engineering ${ }^{4}$, \\ University of Manitoba, Winnipeg, Canada
}

\begin{abstract}
Neural tube defects are serious congenital malformations which can be prevented by periconceptional folic acid supplementation. We hypothesize that folic acid provides the methyl group used for post-translational methylation of arginine and histidine in the highly conserved regulatory domains of the cytoskeleton and that these are required for neural tissue differentiation. Presumptive neural tissue has an unusually high need for folates due to the activity of phosphoethanolamine methyl transferase in producing neural tissue specific lipids at a time when the cytoskeleton is also competing for methylation. According to the cell state splitter hypothesis, the cytoskeleton is required to coordinate the spatial and temporal component of differentiation. When folate supply is low and the cytoskeleton is not methylated properly, the result is a neural tube defect due to failure of this coordination.
\end{abstract}

KEY WORDS: neural tube defect, folic acid, homocysteine, primary neural induction, cytoskeleton

\section{Introduction}

Except for heart defects, neural tube defects (NTDs) are the most common form of major congenital malformation with a birth prevalence of 1-5/1000 births worldwide (Frey and Hauser, 2003). NTDs result from a failure of the rising and fusing of the neural folds during the earliest stages of development. In humans, neural tube closure begins in the third week after conception, often before a woman knows that she is pregnant (Northrup and Volcik, 2000). Due to the high morbidity and mortality associated with NTDs, prenatal diagnosis and elective termination of an affected pregnancy has become the option chosen by $80 \%$ of families faced with an NTD pregnancy (Burton, 1986, Nicolaides, et al., 1986, Benacerraf, et al., 1989). Individuals with spina bifida will undergo multiple surgeries as they grow in order to treat a host of associated problems. Many affected individuals do not survive to adulthood (Bowman, et al., 2001, Rintoul, et al., 2002). While controversial experimental surgical closure of the defect in utero has shown some promise, it does not represent a cure and the surgery is high risk for both mother and fetus (Bannister, 2000, Holmes, et al., 2001).

\section{History of research into folates and NTDs}

The first clue that NTDs might be related to diet came from examining the Dutch famine winter of 1944 , caused by Nazi occupiers. There was a doubling of the incidence of spina bifida among those conceived during the famine. The quality of nutrition was later investigated by gynecologist Hibbard (Hibbard and Smithells, 1965) in the 1960s and pediatrician Smithells in the early 1980s (Smithells, et al., 1985), among others. A series of studies soon pointed to multivitamins and folic acid in particular, as having the ability to prevent NTDs (Czeizel and Rode, 1984). The most widely cited study was published in 1991 (Medical Research Council, 1991). It found that supplementing with $0.4 \mathrm{mg}$ of folic acid per day is capable of preventing $70 \%$ of NTDs in women with a past history of NTDs and $50 \%$ of all NTDs in the general population. Widespread periconceptional supplementation with folic acid has great promise for preventing the majority of isolated NTDs (Eskes, 1998a,b, 2000). Mandatory folic acid food fortification began in the USA on

Abbreviations used in this paper: NTD, neural tube defect; SAH, Sadenosylhomocysteine; SAM, S-adenosylmethionine.

\footnotetext{
*Address correspondence to: Dr. Richard Gordon. Departments of Radiology, Computer Science and Electrical \& Computer Engineering, University of Manitoba, HSC Room GA216, 820 Sherbrook Street, Winnipeg R3A 1R9, MB Canada. Fax: +1-204-787-2080. e-mail: GordonR@ms.umanitoba.ca
} 
January 1, 1998 and prevalence has since dropped to below 5/ 10,000 births (Olney and Mulinare, 2002). Trends in Canada have paralleled those in USA (Gucciardi, et al., 2002, Persad, et al., 2002).

\section{Embryology of NTDs}

The neural epithelium forms a thick flat plate, which then subdivides into multiple embryonic neural tissue types as it folds and seals (Gordon, et al., 1994). NTDs are most commonly thought to occur due to failure of the sides of the neural tube to rise or a failure of the neural tube margins to seal, or some combination thereof. There are multiple explanations of why this failure or failures might occur, but no one explanation is generally accepted (Gordon, 1985, Anon., 1992, Nieuwkoop, 1999, Candito, et al., 2003, McLone, 2003). The failure of any step of differentiation from the initial step of primary neural induction to the end of neural tube closure might result in an NTD. The relative timing of the different zones of differentiation is also critically important to development. For example, if the inner region of the neural plate has faster development compared to the outer edges of the plate, the edges won't meet at a time when they are competent to bind to each other. Such localized differentiations are required in the multi-site closure hypothesis. This hypothesis suggests that there are separate gene(s) expressed at each closure site during neurulation (Van Allen, et al., 1993, Van Allen, 1996). Also, if one zone of the neural plate takes up too small or too large a portion of the whole plate, the mechanical properties of the entire plate might change such that the plate cannot fold properly and roll up to close. In general, the earlier the failure of differentiation, the more severe the neural tube defect (Jones, 1997). Multifactorial NTDs, which represent about $70 \%$ of all NTDs, are thought to be due to a combination of environmental factors and genetic predisposition (Frey and Hauser, 2003), which would have to produce mechanical sequelae of failure of rising and/or sealing of the neural tube.

\section{Folate metabolism and NTDs}

Studying the place of folates in embryological functioning has provided important clues about the etiology of NTDs. Folic acid is an artificial form of folate that is readily converted into the metabolically active derivatives of folate such as ${ }^{5}$ 10 'methylenetetrahydrofolate. Folates, including folic acid, provide a critical methyl group for the creation of a high energy methylating intermediate, $\mathcal{S}$-adenosyl-methionine (SAM). This methylating intermediate is required in enormous quantities for proper construction and functioning of DNA, proteins and lipids. As developing embryos are rapidly creating new cells, they are especially sensitive to reduced levels of folates. Ectoderm and early neural epithelium tissue may be the most sensitive of all embryonic tissues. This idea is supported by the observation that neural plate epithelium expresses extremely high levels of messenger RNA for folate receptors when compared to other embryonic tissues such as the developing heart (Rosenquist, et al., 1996, Rosenquist and Finnell, 2001).

Neural epithelium is also extremely sensitive to homocysteine. Homocysteine concentrations are normally inversely proportional to the concentration of folate derivatives (Fig. 1). Homocysteine is converted to methionine. The enzyme $S$ adenosylmethionine synthase (also known as methionine adenosyltransferase), joins a methionine to an adenosine triphosphate by linking the sulfur of the methionine to the 5' carbon of the ribose unit. This forms the high energy compound SAM (Fig. 2). SAM is the single most important methylating reagent in the cell whose action includes, but is not limited to, the methylation of lysine, arginine and histidine in post-translational modifications of proteins. Critical methylations of DNA, RNA and lipids also require SAM (Miner, et al., 1997).

SAM is converted back to $S$-adenosylhomocysteine (SAH) when the methylation reaction occurs. Several different enzymes catalyze this methylating reaction depending on which compound in the cell requires a methyl group. The product, $S A H$, is a feedback inhibitor of all the enzymes that create SAM and can therefore be regarded as a potentially toxic waste product. The ratio of SAM to SAH in the cell is tightly regulated in each cell type. In normal adult rat liver, SAH exists at $13 \mu \mathrm{mol} / \mathrm{g}$ while SAM is normally at 60 to $90 \mu \mathrm{mol} / \mathrm{g}$ (Skovby, 1989). In the rat embryo, the difference is even more profound with SAM concentration being 42 times higher than SAH in some tissues (Vanaerts, et al., 1994). After the methylation reaction has occurred, the adenosyl group is normally stripped off, leaving homocysteine. Homocysteine must be quickly condensed to cysteine via the pathway called transsulfuration, or recycled back to methionine (remethylation), or exported from the cell, to avoid causing elevated levels of SAH and the resulting inhibiting activity of $\mathrm{SAH}$ on the generation of SAM (see Figs. 1 and 2).

In cultured rat embryos, exposure to a 3 millimol/L concentration of homocysteine in the culture media leads to a drop of the SAM/SAH ratio from 42 to 3.6 (Vanaerts, etal., 1994). Any buildup of homocysteine in the cell results in reversal of the hydrolase reaction that changes $\mathrm{SAH}$ to homocysteine. This causes an increase in SAH levels. This will in turn inhibit the production of SAM, reducing methylation reactions throughout the cell and impeding normal cellular functioning. Amounts of four $\mu \mathrm{mol} / \mathrm{L}$ of homocysteine in culture media can cause NTDs in chick embryos (Rosenquist, et al., 1996).

There are differences between human males and females in terms of metabolism of methionine (Blom, et al., 1988). Females

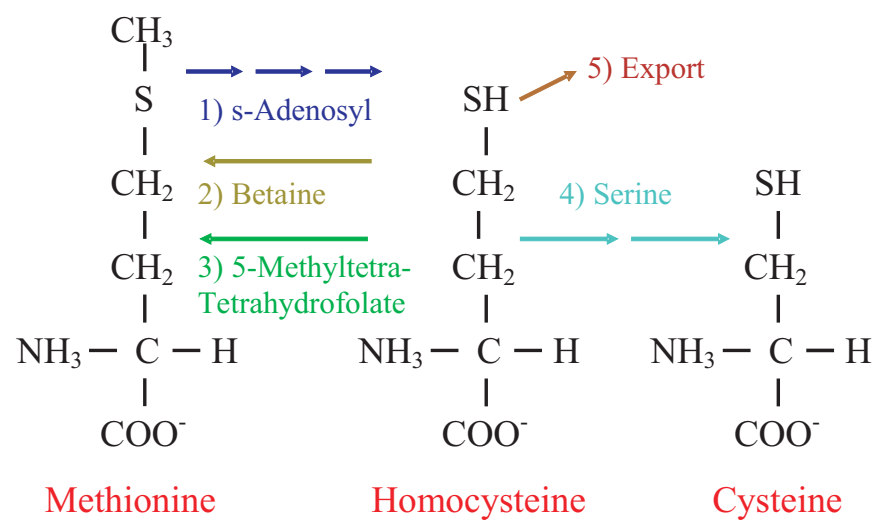

Fig. 1. The structural and enzymatic relationships between methionine, homocysteine and cysteine and the cofactors involved. Arrows represent a single enzymatic reaction. Adapted from Ueland and Refsum, 1989. 


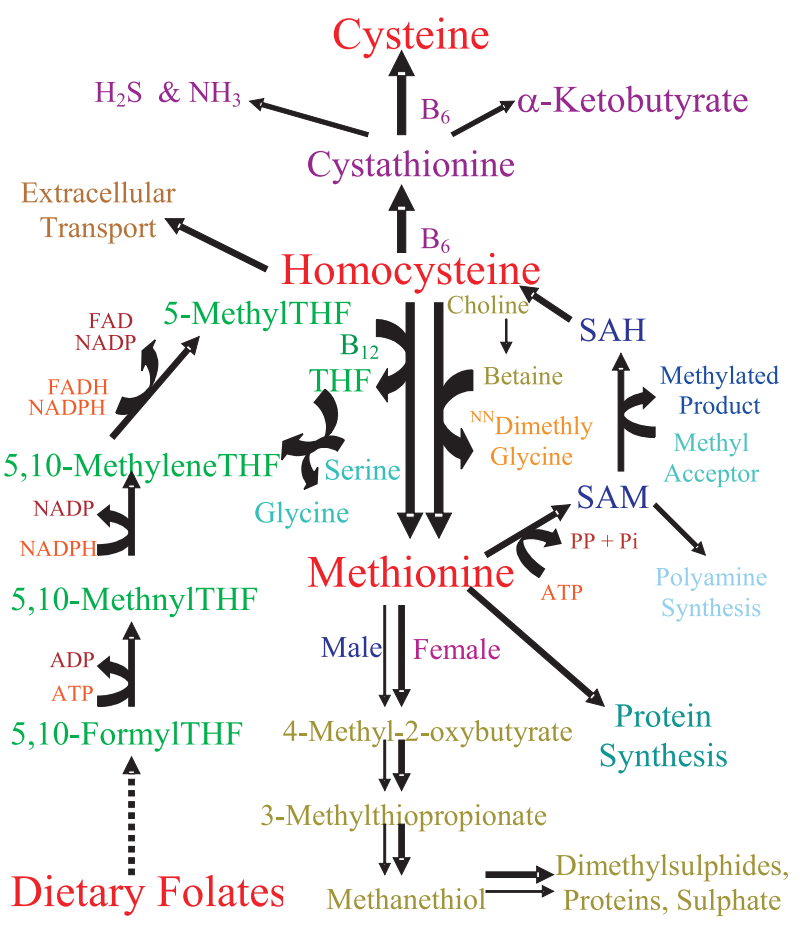

Fig. 2. Basic pathways of homocysteine metabolism. Adapted from Ueland and Refsum, 1989; Vanaerts, et al., 1994 and Blom, 1998.

are more likely to shunt off a portion of the available methionine to 4-methyl-2-oxybutrate in the presence of increased homocysteine. This is because the enzymes in this pathway appear to be enhanced by estrogen. It is unlikely there is any gender based effect at the time of neural tube closure because the embryo is not yet producing significant amounts of its own estrogen and testosterone at that early stage. However, at later stages of pregnancy, there may be survival advantages for one gender over another. The enhancement the 4-methyl-2-oxybutrate pathway offered by estrogen may explain the epidemiological differences in prevalence of males versus females among fetuses with NTDs by allowing differential survival of one gender over the other. Females reach term with anencephaly three times more often than males, see (Elwood and Elwood, 1980).

The human embryo/fetus has both less efficient transsulfuration and remethylation abilities when compared to the adult (Sturman, et al., 1970, Skovby, 1989) (Fig. 3). Yet, the human embryo/fetus nevertheless maintains a much higher SAM/SAH ratio in spite of this dual "impairment". Maintaining the high SAM/SAH ratio in the embryo/fetus can only be accomplished by lowering maternal homocysteine levels. Increasing both transsulfuration and remethylation in the mother, which in fact occurs, can do this. As well, estrogen related compounds enhance removal of methionine from the cycle, which enhances remethylation of homocysteine. Perhaps the dramatic physiologic drop in homocysteine during normal pregnancy of $50 \%$ or more (Andersson, etal., 1992 , Adams, et al., 1995) evolved as a protective mechanism for nurturing a hyperhomocysteinemia susceptible embryo by allowing it to export excess homocysteine.

Even though high levels of homocysteine are toxic to the embryo, the embryo still needs to import some homocysteine as an essential amino acid. This may explain why women who have enzyme variants that increase homocysteine later in pregnancy have been shown to have fewer cases of intrauterine growth restriction (IUGR) among their babies (Infante-Rivard, et al., 2003). The embryo may also control how much homocysteine it imports from the mother and so only suffer problems if both the mother's levels are too high to allow homocysteine export and the embryo is metabolically impaired, so it cannot maintain low levels for itself. Women with homocystinuria due to cystathionine $\beta$ synthase deficiency appear to have normal pregnancy outcomes (Vargas, et al., 1999, Levy, et al., 2002) indicating that high homocysteine levels in the mother are not necessarily a problem for the embryo.

\section{Homocysteine and experimentally induced NTDs}

Cow serum must be supplemented with methionine in order to prevent NTDs in rat embryos grown in vitro on cow serum during the period of neural tube closure (Coelho, et al., 1989). Cow serum is low in methionine and causes low SAM levels in rat embryos. This indicates a critical period of increased requirement for methionine during neural tube closure in rats. This critical period corresponds to the previously noted increased need for folates in neural plate tissues. It would appear that homocysteine is embryotoxic in a general sense. However, it does not directly cause NTDs. Rather, it is the loss of folate derivatives and reduced SAM that cause NTDs. This hypothesis is supported by recent research (Greene, et al., 2003).

Rat embryos grown on low methionine cow serum and with NTDs, have been shown to have reduced amounts of two posttranslational methylations of specific proteins in the neural tissue. Methylation of histidine to form a trimethyl compound was reduced by up to $56 \%$. Methylation of arginine to form a dimethyl compound was reduced by $42 \%$. This effect was not seen in normally developing, but methionine deprived, heart tissue from the same embryo. Methylation of histidine and arginine was normal in embryos that were methionine supplemented and that subsequently developed normally without NTDs (Coelho and Klein, 1990). Why is this specific decrease in methylation re-

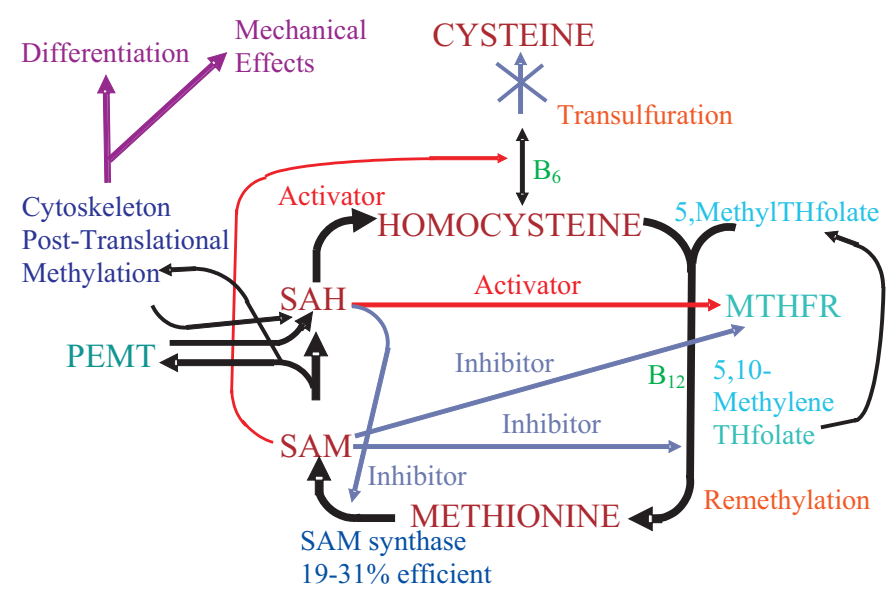

Fig. 3. Embryonic metabolic pathways affecting SAM/SAH levels. 
stricted to rat embryo neural tissue? NTDs may represent a borderline case of SAM deficiency. Too great a deficiency results in death of the embryo. A borderline deficiency affects only embryonic neural tissue because this is the only tissue with elevated SAM demands during the critical period of neural tube closure, at least in rats.

\section{Polyunsaturated fatty acid synthesis may contribute to NTDs}

In adult rats, SAM provides the methyl group for a brain specific phosphoethanolamine methyltransferase(PEMT) enzyme, which preferentially methylates polyunsaturated fatty acids. Most polyunsaturated fatty acids used in the adult are produced in the liver and transported through the blood stream to wherever they are needed (Vance, et al., 1997). PEMT2 is the version of PEMT normally expressed only in adult liver. PEMT2 knockout mice develop normally, from a behavioral perspective, if given choline supplements, because extra phosphotidylcholine is produced via the alternate pathway of phosphorylation of choline. They do have some anatomical brain abnormalities even though their behaviour is normal (Merouani, et al., 2001).

PEMT activity also occurs at very low levels in some other tissue types. There is a brain specific PEMT enzyme required which must exist because polyunsaturated fatty acids cannot pass the blood brain barrier, yet they accumulate in brain tissue (Vance and Ridgway, 1988). This brain specific PEMT has been isolated in newborn rat brain tissue. The PEMT enzyme of neonatal rat brain is different from the adult rat version in the liver. The neonatal PEMT has a high affinity for SAM and methylates four times faster than the adult liver version. Its concentration also increases 2-fold from neonatal days 5 to 20, a period of rapid rat brain growth (Blusztajn, et al., 1985).

Recent research has shown that PEMT activity in the adult liver regulates homocysteine levels. Thus it is not implausible to suggest that there may be a form of PEMT in developing neural tissue that creates polyunsaturated fatty acids in embryonic neural tissue and that this enzyme may also regulate homocysteine in the neural tissue. Certainly changes in homocysteine levels result in changes in brain membrane composition in chick embryos. Increases in homocysteine levels result in decreases in the levels of polyunsaturated fatty acids. The likely mechanism is through inhibition of PEMT by elevations in SAH levels (Noga, et al., 2003).

There is an extremely high demand for neural lipids during early development. The proportion of the neural plate that is made up of cell membrane increases dramatically during neural plate formation and neural tube closure. Individual neural plate cells are both elongating and rapidly dividing (Jacobson and Gordon, 1976, Jacobson and Tam, 1982, Zhu, et al., 2004). This indicates there would be a high demand on any embryonic version of PEMT that might be present in early neural tissue. Normally some of the choline stored in yolk platelets is used for producing phosphorylated choline derivatives such as sphingomyelin. Some of the choline is also converted to betaine, which then acts as a methyl donor for methylation of homocysteine to methionine. This then increases available SAM. In addition, some limited amounts of phosphotidylcholine are normally produced by PEMT during gastrulation and neurulation. However, the betaine pathway is not

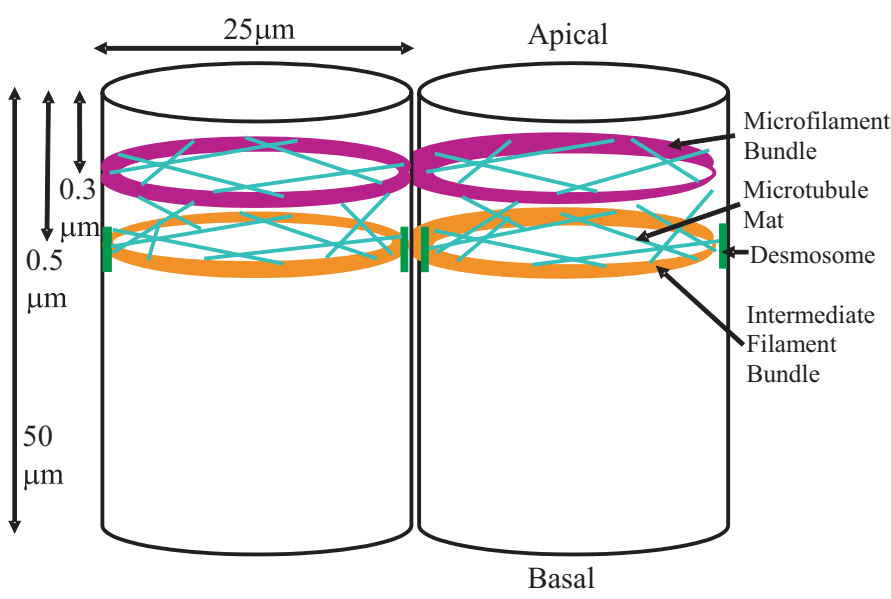

Fig. 4. The apical end of a single ectoderm cell with three cytoskeletal elements forming the bistable organelle, the cell state splitter. In the ectoderm of the axolotl, the cell state splitter consists of a ring of microfilaments at the apical end of the cell, with a ring of intermediate filaments below it. Subtending these rings is an annular ring of microtubules. Desmosomcs connect the cells. The vertical scale is about 30 times larger than the horizontal scale. From (Gordon, et al., 1994) with permission

active until the end of neurulation (Fisher, et al., 2001, 2002). This could then explain why neural tissue is so sensitive to reduced availability of folate derived SAM. During neurulation SAM is only available via the folate pathway. SAM is perhaps also being used up by high affinity PEMT for production of phosphotidylcholine first. Other required methylations such as methylations of histidine and arginine in proteins, cannot be completed because of the lack of methyl groups if there is a shortage of folate.

There are three components of the cytoskeleton that are normally methylated using SAM. These are actin, $\alpha$ and $\beta$ tubulin and neurofilament $L$. The active site of actin and myosin binding has a highly conserved 3-methylhistidine residue. This residue is actively methylated by SAM during neural tube closure. Reduced methylation results in failure of these cytoskeletal elements to localize in the basal and apical ends of the cells (Moephuli, et al., 1997). Failure of appropriate localization of the cytoskeletal elements of neural tissue would result in mechanical failures of cell contractions and movements and thereby cause NTDs. Therefore, reduced methylation of cytoskeletal elements is an ideal candidate for reduced methylation causing changes in differentiation that affect the developing neural plate, which then leads to an NTD.

\section{Cell state splitter and NTDs}

This hypothesis suggests a direct connection between the cytoskeleton and differentiation. While no one model of differentiation is accepted universally, there is a model of neural tissue differentiation that is based on cytoskeletal functioning. This model is called the "cell state splitter model" (Gordon and Brodland, 1987, Gordon, 1999).

Development is generally considered to be a series of bifurcating choices to produce each new cell type. For example, the ectoderm is changed to two new types of tissue, presumptive 
neural epithelium and presumptive epidermal cells. In classical embryological terms, the ectoderm is considered to be on a pathway to forming epidermis unless "induced" to form neural tissue. A signal that induces this alternate pathway of development is presumed to come from the dorsal lip of the blastopore during early gastrulation while mesoderm and endoderm is being tucked inside the embryo and ectoderm is expanding to cover the whole exterior. The primary neural induction signal spreads over half of the ectoderm. The ectoderm changes in response to the induction signal. It begins expressing new gene products unique to neural tissue. The other half of the ectoderm does not receive the induction signal. It, therefore, follows the default program, which is to change gene expression to form the epidermis. Thus, there are two new tissues arising out of one earlier tissue. By continually repeating this process throughout the embryo and in many different tissue types, the entire embryo forms (Schoenwolf and Smith, 1990).

The cell state splitter model of differentiation postulates that the combination of actin, microtubules and intermediate filaments, seen at the apical end of the neural plate cells using electron microscopy (Martin and Gordon, 1997), forms a bistable organelle (the cell state splitter) that is responsible for sensing and then propagating a contraction or expansion wave across presumptive neural epithelium (Fig. 4). The bistability of the device is presumed to account for the binary nature of differentiation, with one nuance: the previous state is not necessarily continued, but one of two new cell states (cell types) is produced when the cell state splitter changes to one of two new stable forms (Gordon, 1985, Gordon and Brodland, 1987, Gordon, 1999).

Many waves of contraction have been observed in the open neural plate of the developing axolotl (Ambystoma mexicanum) (Björklund and Gordon, 1994). The axolotl ectoderm also has its own unique contraction wave and a corresponding expansion wave. The ectoderm contraction wave begins at the dorsal lip of the blastopore at the same time and place that primary neural induction is known to start. Its trajectory is limited to the same region of the ectoderm that is affected by classical primary neural induction, i.e. the presumptive neural plate. After this contraction wave has ended, an expansion wave begins at the bottom of the embryo and travels upward over the region of ectoderm that forms presumptive epidermis. This expansion wave ends at the border of the newly forming neural plate. Both these observed contraction and expansion waves are hypothesized to begin propagating due to a specific mechanical signal (Gordon and Brodland, 1987).

In the case of the axolotl's ectoderm contraction wave, the invaginating pharyngeal endoderm touches the underside of the ectoderm, probably inducing the contraction wave. This particular wave travels over that entire presumptive neural developmental field, moving from cell to cell and thereby propagating the induction signal. The newly forming neural plate cells narrow apically and elongate perpendicularly to the apical surface. The neural plate thereby exerts mechanical pull on the remaining ectoderm tissue in the lower half of the ectoderm. This is hypothesized to start an expansion wave over the remainder of the ectoderm carrying a different signal in this region (Björklund and Gordon, 1994, Gordon, et al., 1994).

The cell state splitter model proposes that while each individual cell is contracting or expanding, a simultaneous chemical signal is sent to the nucleus indicating that the cell has participated in a wave and what kind (Björklund and Gordon, 1993). The nucleus responds to the expansion or contraction wave signal with changes in gene expression that correspond to differentiation into the next cell type (Fig. 5). The trajectory of each wave is shaped and limited by simple mechanical forces in cell sheets. The final stage of differentiation of an individual cell is the preparation of a new cell state splitter capable of responding to and propagating the next wave (except for terminally differentiated cells).

\section{Nuclear state splitter and NTDs}

Contraction and expansion waves provide the spatial and physical component that is missing from most other embryological models (Gordon, 1985, Schoenwolf and Smith, 1990). The classical primary neural induction model is unchanged except that the inducer is a mechanical signal sensed and propagated by cytoskeleton to adjacent cells. The cytoskeleton is specified in this model as that which transduces the mechanical induction signal into a chemical signal. The nucleus senses and responds to the transduced chemical signal, changing its state of gene expression. We therefore speak of a "nuclear state" and "nuclear state splitting". Contrary to the classical model, there is no default state for a tissue type that is not induced. Instead, there is an active change from a previous tissue type to one of two new cell types. The change occurs as a response to which of two types of waves the individual cell actively participates in. Although there is direct correlation between the timing and spatial components of the waves for all the inductions of all presumptive tissue types that appear during axolotl gastrulation, a direct cause and effect relationship remains to be proven (Björklund and Gordon, 1994).

If the cell state splitter model is correct, any malfunction of microfilament function would cause NTDs by preventing contraction waves and thereby preventing localized differentiations in the open neural plate, which would probably alter the mechanics of neural tube closure (Brodland and Clausi, 1994). The reduced

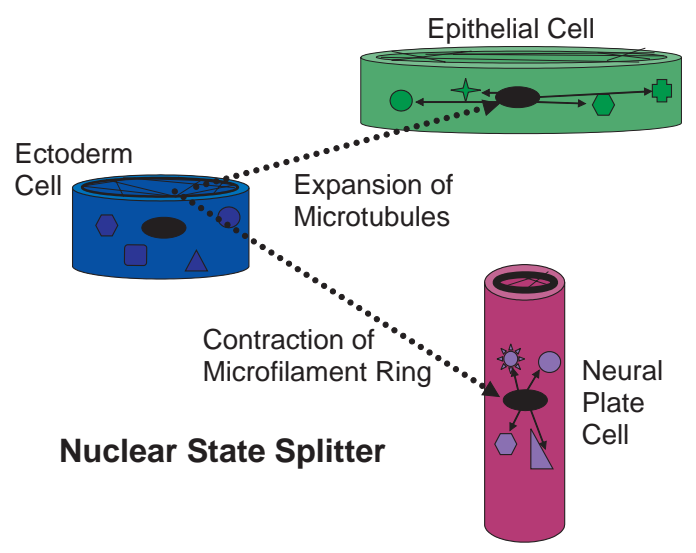

Fig. 5. Schematic of the nuclear state splitter. Schematic of the determination signal sent by the cell state splitter in response to an external signal to expand or contract. The determination signal is then acted upon by the nucleus resulting in changes in expression and differentiation, indicated by short arrows to new gene products. Expansion of microtubules is accomplished by polymerization. Contraction occurs via the microfilament ring. 
methylations of critical regulatory sites may be the underlying mechanism behind multifactorial NTDs. Failures of differentiation may occur because malfunctioning cytoskeletal elements cannot propagate the contraction wave. These cytoskeleton malfunctions could be due to the reduced level of posttranslational methylation in apical cytoskeleton that has been observed in rat embryos with NTDs (Moephuli, et al., 1997). In the embryo affected by an NTD, this particular failure is confined to embryonic neural tissue. The neural tissue is most affected because of its higher SAM requirement relative to other tissues. The higher requirement is due to probable PEMT activity creating new membranes during neural plate formation and closure. This failure (or combination of failures) is circumvented by folic acid supplementation because increasing folate increases SAM levels and perhaps allows proper methylation of the apical cytoskeletal elements of neural epithelium. Any variant enzyme that affects SAM availability is a candidate for the genetic predisposition component of multifactorial NTDs. Reduced folate intake or increased homocysteine become the environmental triggers for NTDs.

Mutations or syndromic conditions that result in the failure of expression of any of the proteins required for cell to cell signaling, cytoskeleton to nucleus signaling, or the subsequent differentiations would also cause NTDs. These types of NTDs would not be folate sensitive (for example, Haigo, et al., 2003). Such mutations or syndromes could account for the $30 \%$ of NTDs that are not prevented by folic acid supplementation. Thus this model interrelates the genetics, epidemiology, morphogenesis and cytoskeletal cell physiology of NTDs.

\section{Summary}

NTDs are serious, common congenital malformations that can be prevented by periconceptional folic acid supplementation. We hypothesize that folic acid provides the methyl group used for posttranslational methylation of arginine and histidine in the highly conserved regulatory domains of the cytoskeleton that is required for neural tissue differentiation (Björklund, 2005). Presumptive neural tissue has an unusually high need for folates due to the activity of phosphoethanolamine methyl transferase in producing neural tissue specific lipids at a time when the cytoskeleton is also competing for methylation. When folate supply is low and the cytoskeleton is not methylated properly, the model predicts that the result is a neural tube defect.

\section{Acknowledgements}

$A$ portion of this work was originally undertaken as part of the background of N.K.B.'s Ph.D. thesis while she was in the department of Human Genetics, University of Manitoba. We would therefore like to thank her thesis co-supervisors Jane A. Evans and CherylR. Greenberg, as well as external examiner, Stephen A. Whitehead and advisors Bernard N. Chodirker and Lorne E. Seargeant, who provided review and commentary. N.K.B. was funded as a graduate student by the Spina Bifida and Hydrocephalus Association of Canada, Children's Hospital Foundation of Manitoba, the Garrod Association of Canada, the Manitoba Medical Services Foundation and University of Manitoba Graduate Fellowships. R.G. was supported in part by the Manitoba Institute for Child Health.

\section{References}

ADAMS, M.J., JR., KHOURY, M.J., SCANLON, K.S., STEVENSON, R.E., KNIGHT, G.J., HADDOW, J.E., SYLVESTER, G.C., CHEEK, J.E., HENRY, J.P., STABLER, S.P. and ALLEN, R.H. (1995). Elevated midtrimester serum methylmalonic acid levels as a risk factor for neural tube defects. Teratology 51:311-317.

ANDERSSON, A., HULTBERG, B., BRATTSTROM, L. and ISAKSSON, A. (1992). Decreased serum homocysteine in pregnancy. Eur. J. Clin. Chem. Clin. Biochem. 30:377-379.

ANON. (1992). Neural tube closure retains its secrets. (1992). Lancet. 339: 218-9

BANNISTER, C.M. (2000). The case for and against intrauterine surgery for myelomeningoceles. Eur. J. Obstet. Gynecol. Reprod. Biol. 92:109-13.

BENACERRAF, B.R., STRYKER, J. and FRIGOLETTO, F.D., JR. (1989). Abnormal US appearance of the cerebellum (banana sign): indirect sign of spina bifida. Radiology 171:151-3.

BJÖRKLUND, N.K. (2005). The Association of the C677T 5,10 methylenetetrahydrofolate reductase Variant with Elevated Maternal Serum $\alpha$ fetoprotein and Complications of Pregnancy. Human Genetics, University of Manitoba, Winnipeg.

BJÖRKLUND, N.K. and GORDON, R. (1993). Nuclear state splitting: a working model for the mechanochemical coupling [Russian]. Ontogenez 24:5-23; (with an Addendum) [English]. Russian J. Dev. Biol. 24:79-95.

BJÖRKLUND, N.K. and GORDON, R. (1994). Surface contraction and expansion waves correlated with differentiation «waves» in axolotl embryos. I. Prolegomenon and differentiation during the plunge through the blastopore, as shown by the fate map. Computers and Chemistry 18:333-345

BLOM, H.J. (1998). Mutated 5,10-methylenetetrahydrofolate reductase and moderate hyperhomocysteinaemia. Eur. J.Pediatr. 157 Suppl. 2:S131-S134.

BLOM, H.J., BOERS, G.H., VAN DEN ELZEN, J.P., VANROESSEL, J.J., TRIJBELS, J.M. and TANGERMAN, A. (1988). Differences between premenopausal women and young men in the transamination pathway of methionine catabolism and the protection against vascular disease. Eur. J. Clin. Invest. 18:633-638.

BLUSZTAJN, J.K., ZEISEL, S.H. and WURTMAN, R.J. (1985). Developmental changes in the activity of phosphatidylethanolamine $\mathrm{N}$-methyltransferases in rat brain. Biochem. J. 232:505-511.

BOWMAN, R.M., MCLONE, D.G., GRANT, J.A., TOMITA, T. and ITO, J.A. (2001) Spina bifida outcome: a 25-year prospective. Pediatr Neurosurg. 34:114-20.

BRODLAND, G.W. and CLAUSI, D.A. (1994). Embryonic tissue morphogenesis modeled by FEM. J. Biomech. Eng. 116:146-55.

BURTON, B.K. (1986). $\alpha$-Fetoprotein screening. Adv.Pediatr. 33:181-196.

CANDITO, M., BOISSON, C., GAUCHERAND, P., LUTON, D., OURY, J.F., BURC, L., JOURNEL, H., RUDIGOZ, R.C. and VAN OBBERGHEN, E. (2003). [Call for researchers associated with a biological study of neural tube defects: prospective study of the role of homocysteine in neural tube defects in France]. Ann. Biol. Clin. (Paris). 61:615-6.

COELHO, C.N. and KLEIN, N.W. (1990). Methionine and neural tube closure in cultured rat embryos: morphological and biochemical analyses. Teratology 42 : 437-451.

COELHO, C.N., WEBER, J.A., KLEIN, N.W., DANIELS, W.G. and HOAGLAND, T.A. (1989). Whole rat embryos require methionine for neural tube closure when cultured on cow serum. J. Nutr. 119:1716-1725.

CZEIZEL, A. and RODE, K. (1984). Trial to prevent first occurrence of neural tube defects by periconceptional multivitamin supplementation. Lancet 2:40.

ELWOOD, M. and ELWOOD, J. (1980). Epidemiology of Anencephalus and Spina Bifida. Oxford University Press, New York.

ESKES, T.K. (1998a). From birth to conception. Open or closed. Eur. J. Obstet. Gynecol. Reprod. Biol. 78: 169-77.

ESKES, T.K. (1998b). Open or closed? A world of difference: a history of homocys teine research. Nutr. Rev. 56:236-44; 313.

ESKES, T.K. (2000). Homocysteine and human reproduction. Clin. Exp. Obstet. Gynecol. 27: 157-67.

FISHER, M.C., ZEISEL, S.H., MAR, M.H. and SADLER, T.W. (2001). Inhibitors of choline uptake and metabolism cause developmental abnormalities in neurulating 
mouse embryos. Teratology 64:114-122.

FISHER, M.C., ZEISEL, S.H., MAR, M.H. and SADLER, T.W. (2002). Perturbations in choline metabolism cause neural tube defects in mouse embryos in vitro. FASEB J. 16:619-621.

FREY, L. and HAUSER, W.A. (2003). Epidemiology of neural tube defects. Epilepsia 44 Suppl. 3:4-13.

GORDON, R. (1985). A review of the theories of vertebrate neurulation and their relationship to the mechanics of neural tube birth defects. J. Embryol. Exp. Morphol. 89 Suppl.:229-255.

GORDON, R. (1999). The Hierarchical Genome and Differentiation Waves: Nove/ Unification of Development, Genetics and Evolution. World Scientific \& Imperial College Press., Singapore \& London.

GORDON, R., BJÖRKLUND, N.K. and NIEUWKOOP, P.D. (1994). Appendix: dialogue on embryonic induction and differentiation waves. Int. Rev. Cytol. 150: 373-420.

GORDON, R. and BRODLAND, G.W. (1987). The cytoskeletal mechanics of brain morphogenesis. Cell state splitters cause primary neural induction. CellBiophys. 11:177-238.

GORDON, R. and JACOBSON, A.G. (1978). The shaping of tissues in embryos. Scientific American 238: 106-113.

GREENE, N.D., DUNLEVY, L.E. and COPP, A.J. (2003). Homocysteine is embryotoxic but does not cause neural tube defects in mouse embryos. Anat. Embryol. (Berl.). 206:185-191.

GUCCIARDI, E., PIETRUSIAK, M.A., REYNOLDS, D.L. and ROULEAU, J. (2002). Incidence of neural tube defects in Ontario, 1986-1999. CMAJ 167:237-240.

HAIGO, S.L., HILDEBRAND, J.D., HARLAND, R.M. and WALLINGFORD, J.B. (2003). Shroom induces apical constriction and is required for hingepoint formation during neural tube closure. Curr. Biol. 13:2125-2137.

HIBBARD, E.D. and SMITHELLS, R.W. (1965). Folic acid metabolism and human embryopathy. Lancet /:1254-1256.

HOLMES, N.M., NGUYEN, H.T., HARRISON, M.R., FARMER, D.L. and BASKIN, L.S. (2001). Fetal intervention for myelomeningocele: effect on postnatal bladder function. J. Urol. 166:2383-2386.

INFANTE-RIVARD, C., RIVARD, G.E., GAUTHIER, R. and THEORET, Y. (2003). Unexpected relationship between plasma homocysteine and intrauterine growth restriction. Clin. Chem. 49:1476-1482.

JACOBSON, A.G. and GORDON, R. (1976). Changes in the shape of the developing vertebrate nervous system analyzed experimentally, mathematically and by computer simulation. J. Exp. Zool. 197:191-246.

JACOBSON, A.G. and TAM, P.P. (1982). Cephalic neurulation in the mouse embryo analyzed by SEM and morphometry. Anat. Rec. 203:375-96.

JONES, K.L. (1997). Smith's Recognizable Patterns of Human Malformation. (5 ${ }^{\text {th }}$ Ed.) W.B. Saunders Company, Philadephia.

LEVY, H.L., VARGAS, J.E., WAISBREN, S.E., KURCZYNSKI, T.W., ROEDER, E.R., SCHWARTZ, R.S., ROSENGREN, S., PRASAD, C., GREENBERG, C.R., GILFIX, B.M., MACGREGOR, D., SHIH, V.E., BAO, L. and KRAUS, J.P. (2002). Reproductive fitness in maternal homocystinuria due to cystathionine betasynthase deficiency. J. Inherit. Metab. Dis. 25:299-314.

MARTIN, C.C. and GORDON, R. (1997). Ultrastructural analysis of the cell state splitter in ectoderm cells differentiating to neural plate and epidermis during gastrulation in embryos of the axolotl Ambystoma mexicanum. Russian J. Dev. Biol. 28: 71-80.

MCLONE, D.G. (2003). The etiology of neural tube defects: the role of folic acid. Child's Nerv. Syst. 19:537-9.

MEDICAL RESEARCH COUNCIL (1991). Prevention of neural tube defects: results of the Medical Research Council Vitamin Study. MRC Vitamin Study Research Group. Lancet 338: 131-137.

MEROUANI, A., LAMBERT, M., DELVIN, E.E., GENEST, J., JR., ROBITAILLE, P. and ROZEN, R. (2001). Plasma homocysteine concentration in children with chronic renal failure. Pediatr. Nephrol. 16:805-811.

MINER, S.E., EVROVSKI, J. and COLE, D.E. (1997). Clinical chemistry and molecular biology of homocysteine metabolism: an update. Clin. Biochem. 30 : 189-201.
MOEPHULI, S.R., KLEIN, N.W., BALDWIN, M.T. and KRIDER, H.M. (1997). Effects of methionine on the cytoplasmic distribution of actin and tubulin during neural tube closure in rat embryos. Proc. Natl. Acad. Sci. USA 94:543-548.

NICOLAIDES, K.H., CAMPBELL, S., GABBE, S.G. and GUIDETTI, R. (1986). Ultrasound screening for spina bifida: cranial and cerebellar signs. Lancet 2:7274.

NIEUWKOOP, P.D. (1999). The neural induction process; its morphogenetic aspects. Int. J. Dev. Biol. 43:615-23.

NOGA, A.A., STEAD, L.M., ZHAO, Y., BROSNAN, M.E., BROSNAN, J.T. and VANCE, D.E. (2003). Plasma homocysteine is regulated by phospholipid methylation. J. Biol. Chem. 278:5952-5955.

NORTHRUP, H. and VOLCIK, K.A. (2000). Spina bifida and other neural tube defects. Curr. Probl. Pediatr. 30:313-332.

OLNEY, R.S. and MULINARE, J. (2002). Trends in neural tube defect prevalence, folic acid fortification and vitamin supplement use. Semin. Perinatol. 26:277285.

PERSAD, V.L., VAN DEN HOF, M.C., DUBE, J.M. and ZIMMER, P. (2002). Incidence of open neural tube defects in Nova Scotia after folic acid fortification. CMAJ 167:241-245.

RINTOUL, N.E., SUTTON, L.N., HUBBARD, A.M., COHEN, B., MELCHIONNI, J., PASQUARIELLO, P.S. and ADZICK, N.S. (2002). A new look at myelomeningoceles: functional level, vertebral level, shunting and the implications for fetal intervention. Pediatrics 109: 409-413.

ROSENQUIST, T.H. and FINNELL, R.H. (2001). Genes, folate and homocysteine in embryonic development. Proc. Nutr. Soc. 60:53-61.

ROSENQUIST, T.H., RATASHAK, S.A. and SELHUB, J. (1996). Homocysteine induces congenital defects of the heart and neural tube: effect of folic acid. Proc. Natl. Acad. Sci. USA 93:15227-15232.

SCHOENWOLF, G.C. and SMITH, J.L. (1990). Mechanisms of neurulation: traditional viewpoint and recent advances. Development 109:243-270.

SKOVBY, F. (1989). Inborn errors of metabolism causing homocysteinemia and related vascular involvement. Haemostasis 19 Suppl. 1:4-9.

SMITHELLS, R.W., SHEPPARD, S., WILD, J., SCHORAH, C.J., FIELDING, D.W., SELLER, M.J., NEVIN, N.C., HARRIS, R., READ, A.P. and WALKER, S. (1985). Neural-tube defects and vitamins: the need for a randomized clinical trial. $B r . J$. Obstet. Gynaecol. 92:185-8.

STURMAN, J.A., GAULL, G. and RAIHA, N.C. (1970). Absence of cystathionase in human fetal liver: is cystine essential? Science 169:74-76.

UELAND, P.M. and REFSUM, H. (1989). Plasma homocysteine, a risk factor for vascular disease: plasma levels in health, disease and drug therapy. J. Lab. Clin.Med. 114: 473-501.

VAN ALLEN, M.I. (1996). Multisite neural tube closure in humans. Birth Defects Orig. Artic. Ser. 30:203-225.

VAN ALLEN, M.I., KALOUSEK, D.K., CHERNOFF, G.F., JURILOFF, D., HARRIS, M., MCGILLIVRAY, B.C., YONG, S.L., LANGLOIS, S., MACLEOD, P.M. and CHITAYAT, D. (1993). Evidence for multi-site closure of the neural tube in humans. Am. J. Med. Genet. 47:723-743.

VANAERTS, L.A., BLOM, H.J., DEABREU, R.A., TRIJBELS, F.J., ESKES, T.K., COPIUS PEEREBOOM-STEGEMAN, J.H. and NOORDHOEK, J. (1994). Prevention of neural tube defects by and toxicity of L-homocysteine in cultured postimplantation rat embryos. Teratology 50:348-360.

VANCE, D.E. and RIDGWAY, N.D. (1988). The methylation of phosphatidylethanolamine. Prog. Lipid Res. 27:61-79.

VANCE, D.E., WALKEY, C.J. and CUI, Z. (1997). Phosphatidylethanolamine Nmethyltransferase from liver. Biochim. Biophys. Acta 1348:142-150.

VARGAS, J.E., MUDD, S.H., WAISBREN, S.E. and LEVY, H.L. (1999). Maternal gamma-cystathionase deficiency: absence of both teratogenic effects and pregnancy complications. Am. J. Obstet. Gynecol. 181:753-5.

ZHU, X., MAR, M.H., SONG, J. and ZEISEL, S.H. (2004). Deletion of the Pemt gene increases progenitor cell mitosis, DNA and protein methylation and decreases calretinin expression in embryonic day 17 mouse hippocampus. Brain Res. Dev. Brain Res. 149:121-129. 